UC3M Working Papers

Economics

15-02

ISSN 2340-5031

February 2015

\title{
Optimal Unemployment Insurance: Consumption versus Expenditure ${ }^{1}$
}

\author{
Rodolfo Campos ${ }^{\dagger}$ and Iliana Reggio ${ }^{\ddagger}$
}

\begin{abstract}
We study the optimal provision of unemployment insurance (UI) in a framework that distinguishes between consumption and expenditure. We derive a "sufficient statistics" formula for optimal UI that is expressed terms of observable variables and can therefore be used in applied work. Recent research has shown that unemployed households pay less per unit of consumption than employed households. This finding has two counteracting effects on the optimal level of UI. On the one hand, consumption smoothing benefits identified from expenditure data overestimate the true marginal benefits of UI. On the other hand, UI benefits become more valuable because they buy more consumption when unemployed. In an optimal design, which effect dominates depends on the curvature of the utility function. We show that for relative risk aversion larger than one the first effect dominates, leading to lower levels of optimal UI.
\end{abstract}

JEL classification: D11, J64, J65, J68.

Keywords: consumption, expenditure, consumption-smoothing, social insurance, unemployment insurance.

1 We gratefully acknowledge financial support by the Spanish Ministerio de Economía y Competitividad (Grants ECO2012-38134 and ECO2012-31358).

† Department of Economics, IESE Business School, Camino del Cerro del Águila 3, 28023 Madrid, Spain; email: rcampos@iese.edu.

$\ddagger$ Department of Economics, Universidad Carlos III, Calle Madrid 126, 28903 Getafe (Madrid), Spain; email: ireggio@eco.uc3m.es. 


\section{Introduction}

A central question in an unemployment insurance scheme is how generous the program should be. Because providing consumption insurance distorts incentives to search for a new job, optimal insurance design takes into account the efficiency costs induced by moral hazard. These costs must be balanced against the welfare gains brought about by insuring workers against consumption drops due to unemployment. From an empirical perspective, the potential welfare gains of consumption-smoothing can be quantified by the drop in consumption experienced upon unemployment. The size of this drop has been estimated time and again - sometimes without a direct reference to unemployment insurance - , for example by Cochrane (1991), Gruber (1997), Browning and Crossley (2001), and Stephens (2001). A characteristic shared by these studies is that, because of the data available, they focus on consumption expenditure (price times quantity) rather than on consumption (quantity).

The neglect to empirically distinguish between consumption and expenditure may be inconsequential if prices paid per unit of consumption do not differ between the employed and the unemployed. If, however, part of the consumption drop at unemployment is due to the unemployed paying lower prices, then the drop in expenditure will overstate the drop in consumption. If this is the case, then potential consumption-smoothing benefits will be exaggerated and, as a general rule, the calibration of optimal insurance levels using empirical estimates based exclusively on expenditure data will be inaccurate.

The problem is not solely of an empirical nature. The fact that the unemployed pay lower prices changes the social insurance design problem itself. Lower prices for the unemployed imply that a dollar buys more consumption in the unemployed state of the world than in the employed state of the world. Therefore, relative to a case in which the price of consumption is constant across the employed and unemployed state, a social planner would optimally choose to transfer more resources into the unemployed state and therefore raise the degree of social insurance.

There is now a host of evidence that indicates that the unemployed pay lower prices than their employed counterparts. This evidence suggests that activities such as shopping and searching for bargains play a role in lowering prices. Using time use surveys, Aguiar, Hurst, and Karabarbounis (2013) find that the unemployed devote more time to shopping: in the United States, roughly 7 percent of the time freed up by market hours 
of work is dedicated to activities such as shopping for groceries and other household items, comparison shopping, coupon clipping, and buying goods online. In comparison, only between 2 and 6 percent of the time freed up is used to increase job search. Krueger and Mueller (2012) corroborate this finding in an international sample by studying time use surveys from 14 different countries.

Increased shopping time translates into lower prices. Using supermarket scanner data, Aguiar and Hurst (2007) verify that increased shopping effort lowers the price paid for grocery items while maintaining quality constant in the general population. Aguiar and Hurst (2005) focus specifically on the unemployed and find that expenditure by the unemployed falls more than consumption, indicating a reduction in the price paid per unit of consumption.

In this paper we study how distinguishing between expenditure and consumption, affects the level of optimal unemployment insurance. Acknowledging that expenditure is not the same as consumption has two countervailing effects on the optimal benefit level. On the one hand, optimal unemployment insurance takes into account that the unemployed have access to lower prices in the unemployed state. Because a given dollar amount buys more consumption in the unemployed state, from the perspective of a benevolent social planner, it becomes worthwhile to transfer income from the good to the bad state. This effect tilts the balance in favor of more generous unemployment benefits. On the other hand, estimations that rely on expenditure data will over-estimate the consumption-smoothing benefit of unemployment insurance because they disregard the change in prices. A correct measurement therefore tilts the balance in the direction of lower optimal unemployment benefits.

We formalize these ideas by adapting the standard normative model of social insurance originally due to Baily (1978). Chetty (2006) showed that Baily's setup captures the main trade-offs that arise in fully intertemporal settings in the style of those considered by Shavell and Weiss (1979) and Hopenhayn and Nicolini (1997). The Baily-Chetty model is part of a general class of models in public economics in which optimal policies can be computed from a reduced number of sufficient statistics. ${ }^{1}$ In this model, optimal unemployment benefits are described by a simple formula that involves only three sufficient statistics: the magnitude of the consumption drop experienced at unemploy-

\footnotetext{
${ }^{1} \mathrm{~A}$ detailed analysis of the advantages and disadvantages of the "sufficient statistics" approach, as well as the history of its use in public economics, is provided by Chetty (2009). The famous dead-weight loss calculation by Harberger (1964) is an early example of this approach.
} 
ment, the level of relative risk-aversion, and the elasticity of unemployment duration with respect to the benefit level.

We depart from the Baily-Chetty model by allowing agents to endogenously choose how much of the time freed up by not working they devote to shopping activities. By increasing shopping time they reduce prices paid for consumption. The social planner sets optimal unemployment benefits taking into account responses by workers, in particular the endogenous choice of shopping time. As usual in this literature, because of the Envelope Theorem, several endogenous choices do not have a first-order effect on optimal benefit levels. An important feature of our model is that shopping affects state-prices and therefore the implicit return of transferring resources across states faced by the social planner.

In comparison to the standard first order condition of the social planner in the BailyChetty model, marginal utility of the worker in the unemployed state is scaled upward by the gross return of transferring resources across states. This first order condition could be used to inform policy on the optimal level of unemployment insurance if consumption were directly observable. Because consumption is usually not observed in real-world data, we show how the optimality condition can be re-expressed in terms of expenditure. If the worker's preferences can be described by a constant relative risk-aversion (CRRA) utility function, then optimal policy can be expressed in terms of expenditure in a generalized version of the standard Baily-Chetty formula. Whether optimal benefit levels obtained from expenditure data should be revised upward or downward depends exclusively in the degree of relative risk aversion. We show that, under the usual assumption of relative risk aversion greater than one, estimations based on expenditure data systematically over-estimate the level of optimal unemployment benefits.

To illustrate the empirical relevance of our theoretical result, we calibrate our formula to US data following the approach of Gruber (1997). We find that, when compared to the standard Baily-Chetty formula, if the the price paid by the unemployed is $5 \%$ lower than what the employed pay for their consumption, then, for levels of risk aversion slightly above two, replacement rates are at least 10 percentage points lower. For example, for a level of relative risk-aversion of 3 , the optimal replacement rate according to the standard formula is $38.6 \%$ whereas it is $25.7 \%$ in the formula that takes into account the distinction between consumption and expenditure.

Because of the way the distinction between consumption and expenditure enters the 
social planner's maximization problem, it will be of relevance not only for the canonical Baily-Chetty model but also for the class of social insurance models that generalize their environment and obtain similar "sufficient statistics" formulas. We show how the wedge introduced by the distinction between consumption and expenditure can inform these related models. Notably, this wedge does not depend on the elasticity measuring the behavior that leads to moral hazard by the insured population. It is, however, influenced by the difference in prices paid in the good and the bad state of the world. Therefore, empirical research on economic shocks that distinguishes between consumption and expenditure holds important insights for social insurance in general.

\section{Model}

We build on the two-period model used by Baily (1978) and Chetty (2006) to derive their formula for optimal unemployment insurance. We extend the Baily-Chetty model by distinguishing between consumption and expenditure and by allowing for additional uses of free time. Unemployed workers can choose to use their free time on activities that lower the price they pay for consumption.

\subsection{The environment}

There are two dates: 0 and 1 . A risk-averse worker, who derives utility from consumption and leisure, arrives at date 0 with assets $A$ and lives for one period until date 1 . At date 0 , the worker may become unemployed with exogenous probability $\pi$ and stays employed with probability $1-\pi$. If employed, the worker supplies one unit of labor and obtains a wage rate $w$. A worker who becomes unemployed stays unemployed for a fraction of time $D \in[0,1]$, the unemployment duration, during which labor earnings are zero.

As in the Baily-Chetty model, unemployment insurance is parameterized by the pair $(b, \tau)$, where $b$ denotes the benefit received by an unemployed agent and $\tau$ is the tax paid (only by fully employed workers) to sustain the insurance scheme. To maintain a balanced budget, the unemployment insurance scheme must satisfy

$$
(1-\pi) \tau=\pi b D
$$


A benevolent planner chooses the parameters of the social insurance scheme so as to maximize the worker's welfare while maintaining budget balance and taking into account the worker's optimal response to the social insurance parameters $b$ and $\tau$.

\subsection{Time allocation}

Unemployed workers can influence the unemployment duration $D$ by varying their job search effort. Chetty (2006) did not directly model time use when unemployed and posited a function that indirectly embeds the time costs of search and utility of leisure. In his model, this function is assumed to be increasing in $D$ and concave. Because we consider the case in which agents have an additional use for their time, we focus in more detail on the allocation of time when unemployed.

During the duration of unemployment $D$, the agent can allocate the time freed up by not working to three alternative activities: leisure $\ell$, job search $t_{D}$, and price search $t_{p}$. These variables are measured as additional time spent on these activities net of time already spent on them in the employed state. The time spent on these three activities is limited by the following time constraint:

$$
\ell+t_{D}+t_{p} \leq D
$$

That is, the sum of additional time spent on all three activities is bounded by total time available $D$, the duration of unemployment. ${ }^{2}$

Leisure has a direct payoff in utility terms. Utility derived from the extra leisure when unemployed is captured by the function $\nu(\ell)$, with $\nu^{\prime}(\cdot)<0$ and $\nu^{\prime \prime}(\cdot) \leq 0$. We normalize $\nu(0)=0$, so that $\nu(\ell)$ measures utility gains over leisure enjoyed in the employed state.

Time spent on job search reduces the duration of unemployment. As in the model of Chetty (2006), we assume that the agent controls the duration $D$ deterministically. This is captured by the relationship $D=\delta\left(t_{D}\right)$. This function $\delta:[0,1] \rightarrow[0,1]$ satisfies $\delta^{\prime}(\cdot)<0$ and $\delta^{\prime \prime}(\cdot)>0$. Time spent on job search reduces the duration at a decreasing rate. Analogously, time spent on the search for lower prices $t_{p}$ converts into prices according to a function $p=\sigma\left(t_{p}\right)$, with $\sigma^{\prime}(\cdot)<0$ and $\sigma^{\prime \prime}(\cdot)>0$. Shopping time reduces prices, albeit at a decreasing rate. This functional form is directly motivated by the

\footnotetext{
${ }^{2}$ For employed workers this constraint holds trivially with $D=\ell=t_{D}=t_{p}=0$.
} 
existing literature that relates shopping effort to purchase prices (e.g., Aguiar and Hurst, 2007). ${ }^{3}$

We normalize the price of the consumption good in the employed state to 1 , so that $p \leq 1$ represents the relative price per unit of consumption in the unemployed state. ${ }^{4}$ Moreover, even if the agent uses all the available time on price search, goods cannot be obtained for free. This is formalized by introducing a lower bound for prices at $p>0$, so that the function $\sigma:[0,1] \rightarrow[\underline{p}, 1]$. This lower bound on prices is important in ensuring that consumption in the unemployed state is bounded away from infinity in the agent's maximization problem.

\subsection{The worker's and the planner's problem}

Taking the unemployment insurance parameter pair $(b, \tau)$ as given, the worker chooses consumption in the employed state $c_{e}$, consumption in the unemployed state $c_{u}$, and time allocations when unemployed $\left\{\ell, t_{D}, t_{p}\right\}$ to maximize expected utility defined as

$$
(1-\pi) u\left(c_{e}\right)+\pi\left\{u\left(c_{u}\right)+\nu(\ell)\right\}
$$

The choices of the worker are constrained by the time constraint (2) and two budget constraints, one for each state,

$$
\begin{gathered}
A+(w-\tau)-c_{e} \geq 0, \\
A+b D+w(1-D)-p c_{u} \geq 0 .
\end{gathered}
$$

The worker also takes into account how $t_{D}$ and $t_{p}$ affect $D$ and $p$ through the functions

$$
D=\delta\left(t_{D}\right), \quad p=\sigma\left(t_{p}\right)
$$

Taking the optimal choices of the worker as given, the planner maximizes indirect utility defined over the unemployment insurance parameter pair $(b, \tau)$ subject to the balanced

\footnotetext{
${ }^{3}$ Aguiar and Hurst (2007) postulate (and empirically verify in their data) a specification in which the price paid is decreasing in shopping time, with the returns to shopping diminishing as shopping intensity increases.

${ }^{4}$ Because for employed agents $t_{p}=0$, in terms of the function $\sigma$, this implies the normalization $\sigma(0)=1$.
} 
budget constraint (1).

\subsection{A simplified worker's problem}

To make the problem formally comparable to the model of Chetty (2006), we show how the worker's problem can be simplified. Non-satiation in leisure implies that (2) will hold with equality. Moreover, because the functions $\delta$ and $\sigma$ are strictly decreasing they admit an inverse function. Using the time constraint, leisure can be expressed in terms of these inverse functions and the variables $D$ and $p$ :

$$
\ell(D, p)=D-\delta^{-1}(D)-\sigma^{-1}(p)
$$

Using (7), the leisure term in utility when unemployed can be expressed as a function of $D$ and $p$ :

$$
\nu(\ell(D, p)) \equiv \psi(D, p)
$$

The additive separability in (7), together with functional forms of $\nu, \delta$, and $\sigma$, imply for $\psi(D, p)$ that $\psi_{D}>0, \psi_{D D}<0, \psi_{p}>0, \psi_{p p}<0$, and $\psi_{D p} \leq 0 .^{5}$

Using this substitution, the worker's problem can be restated as the choice of consumption when employed $c_{e}$, consumption when unemployed $c_{u}$, the duration of unemployment $D$, and the price $p$ to maximize

$$
(1-\pi) u\left(c_{e}\right)+\pi\left\{u\left(c_{u}\right)+\psi(D, p)\right\}
$$

subject to

$$
\begin{gathered}
A+(w-\tau)-c_{e} \geq 0 \\
A+b D+w(1-D)-p c_{u} \geq 0
\end{gathered}
$$

Formally, the worker's problem differs from the model of Chetty (2006) in the additional choice variable $p$ that appears in two places in the worker's problem: in the utility function inside the term $\psi(D, p)$ and in the budget constraint of the unemployed. The

\footnotetext{
${ }^{5}$ Whether this last inequality is strict depends on the concavity of the leisure term in the utility function. If $\nu^{\prime}(\cdot)<0$, then $\psi_{D p}<0$; if $\nu^{\prime}(\cdot)=0$, then $\psi_{D p}=0$. In this last case, $\nu$ is linear and $\psi(D, p)$ can be written as the sum of two separate increasing and strictly concave functions $\psi_{1}(D)$ and $\psi_{2}(p)$.
} 
model of Chetty (2006) is obtained as the special case in which $p=1$ (meaning $t_{p}=0$ ). In this case, $\psi(D, 1)$ varies only with $D$ (and is strictly increasing and concave in this variable), and the relative price $p$ effectively disappears from the budget constraint.

\subsection{A characterization of optimal unemployment insurance}

Let $V(b, \tau)$ stand for the indirect utility of the worker. The optimal unemployment insurance scheme that satisfies budget balance is for the planner to choose $b$ and $\tau$ to maximize $V(b, \tau)$ subject to (1). The following proposition characterizes the first order condition of the social planner's problem.

Proposition 1 The marginal net benefit of a balanced-budget increase of $b$ is given by

$$
\frac{d V(b, \tau(b))}{d b}=\pi D\left[\frac{1}{p} u^{\prime}\left(c_{u}\right)-\left(1+\varepsilon_{D, b}\right) u^{\prime}\left(c_{e}\right)\right]
$$

where $\varepsilon_{D, b}$ is the elasticity of the duration of unemployment with respect to the unemployment insurance benefit $b$ :

$$
\varepsilon_{D, b}=\frac{b}{D} \frac{d D}{d b}
$$

Proof. The indirect utility function that the planner maximizes can be written fully in terms of $b$. Using the $\lambda_{e}$ and $\lambda_{u}$ to denote the Lagrange multipliers of the two budget constraints in the worker's problem, the indirect utility function $V(b, \tau(b))$ is equal to

$$
\begin{aligned}
V(b, \tau(b))= & \max _{c_{e}, c_{u}, D, p, \lambda_{e}, \lambda_{u}}(1-\pi) u\left(c_{e}\right)+\pi\left\{u\left(c_{u}\right)+\psi(D, p)\right\} \\
& +\lambda_{e}\left[A+(w-\tau(b))-c_{e}\right]+\lambda_{u}\left[A+b D+w(1-D)-p c_{u}\right]
\end{aligned}
$$

Because this expression is optimized over $\left\{c_{e}, c_{u}, D, p, \lambda_{e}, \lambda_{u}\right\}$, by the Envelope Theorem, changes in these variables do not have first-order effects on $V(b, \tau(b))$. Therefore,

$$
\frac{d V(b, \tau(b))}{d b}=-\lambda_{e} \frac{d \tau(b)}{d b}+\lambda_{u} D
$$

Agent optimization implies

$$
\lambda_{e}=(1-\pi) u^{\prime}\left(c_{e}\right)
$$


and

$$
p \lambda_{u}=\pi u^{\prime}\left(c_{u}\right)
$$

Finally, differentiating the government's budget constraint,

$$
\frac{d \tau(b)}{d b}=\frac{\pi}{1-\pi}\left[D+b \frac{d D}{d b}\right]
$$

Substitute $\lambda_{e}, \lambda_{u}$, and the derivative $\frac{d \tau(b)}{d b}$ in (15) using the first order conditions (16) and (17), and (18). After these substitutions, and rearranging, (15) becomes

$$
\frac{d V(b)}{d b}=\pi D\left[\frac{1}{p} u^{\prime}\left(c_{u}\right)-\left[1+\frac{b}{D} \frac{d D}{d b}\right] u^{\prime}\left(c_{e}\right)\right] .
$$

Applying the definition of the elasticity, the exact expression in the Proposition is obtained.

Q.E.D.

The resulting equation is formally equivalent to a formula with a state-dependent utility function in which the marginal utility in the unemployed state is (endogenously) shifted upward. Because purchasing consumption in the unemployed state costs only $p \leq 1$, transferring resources from the employed to the unemployed state has an endogenous gross return of $\frac{1}{p} \geq 1$. Unless unemployed workers decide to spend absolutely no time on shopping, this gross return is strictly greater than one.

In terms of economic intuition, the expression in (12) states that the value of an additional dollar in the unemployed state is proportional to the gross return of transferring resources into that state times the marginal utility of consuming in that state: $\frac{1}{p} u^{\prime}\left(c_{u}\right)$. The cost of providing this additional dollar is the consumption foregone in the employed state, which is measured by $u^{\prime}\left(c_{e}\right)$ plus the behavioral effect $u^{\prime}\left(c_{e}\right) \varepsilon_{D, b}$ that takes into account reduced job search effort.

In the case of an interior optimum, $b^{*}$ is implicitly defined by setting $\frac{d V(b)}{d b}=0$. This yields the following condition:

$$
\frac{u^{\prime}\left(c_{u}\right)}{u^{\prime}\left(c_{e}\right)}=p\left[1+\varepsilon_{D, b}\right]
$$

At the optimal benefit level the marginal rate of substitution is equal to the behavioral elasticity of Baily (1978) and Chetty (2006) times the ratio of the endogenously chosen state-prices $p$. 
Notably absent from the expression in (20) is the welfare cost related to reducing leisure in order to free up time for shopping. This is not because it was not taken into account. A first order condition for the unemployed worker equates the disutility from spending more time on price search to the benefits arising from relaxing the budget constraint in the unemployed state of the world. ${ }^{6}$ The reason is that the variables showing up in (20) are sufficient statistics for the optimal benefit level. As is usual in the "sufficient statistics" literature, all the information necessary to solve for the optimal benefit level $b^{*}$ is embedded in the equilibrium values of a relatively small number of variables.

\subsection{Optimal unemployment insurance in terms of consumption expenditure}

The optimality condition in (20) is not expressed in terms of observational data. The empirical relationship between consumption and unemployment is usually estimated from data on consumption expenditure, not consumption. We re-express the equation in terms of observables. Expenditure in the unemployed state is $\tilde{c}_{u}=p c_{u}$ and expenditure in the employed state is $\tilde{c}_{e}=c_{e}$. In what follows we assume a CRRA specification, which leads to $u^{\prime}(c)=c^{-\gamma}$, where $\gamma>0$ is the level of relative risk aversion.

By using the CRRA specification, and taking logs on both sides, we arrive at a condition purely in terms of observational data:

$$
\gamma \Delta \log \tilde{c}=\log \left(1+\varepsilon_{D, b}\right)+(1-\gamma) \log p
$$

where $\Delta \log \tilde{c} \equiv \log \tilde{c}_{e}-\log \tilde{c}_{u}$ is the $\log$-difference of expenditure between the employed and the unemployed state.

The expression in (21) is an exact relationship. To compare it with the standard BailyChetty formula, we can take a first-order approximation to this equation. ${ }^{7}$ Doing so results in

$$
\gamma \frac{\Delta \tilde{c}}{\tilde{c}} \approx \varepsilon_{D, b}+(1-\gamma)(p-1)
$$

This expression generalizes the standard Baily-Chetty formula. Notice that if either

\footnotetext{
${ }^{6}$ In the worker's problem, the first order condition with respect to $p$ implies $\psi_{p}=\lambda_{u} c_{u}$.

${ }^{7}$ To obtain this approximation, on the left hand side of the expression, write $\Delta \log \tilde{c}=\log \left(1+\frac{\Delta \tilde{c}}{\tilde{c}}\right)$. Then, on both sides of the equation, use the approximation $\log (1+z) \approx z$.
} 
$p=1$ or $\gamma=1$ (in either the exact or approximate expression), then the price $p$ does not play a role. In this case, the Baily-Chetty formula is obtained as a special case of $(22)$.

The case in which $p=1$ has a straightforward explanation; if the unemployed are unwilling or unable to lower the prices paid, because they do not spend time searching for lower prices, then the distinction between consumption and expenditure becomes irrelevant for the optimal choice of $b$. The second case, in which $\gamma=1$ has a less mechanical explanation. When the degree of risk-aversion is 1 , preferences are equivalent to a Cobb-Douglass utility function, which have a unitary elasticity of substitution. Therefore, optimal expenditure choices do not respond to changes in relative prices and, again, the distinction between consumption and expenditure becomes irrelevant for the optimal choice of $b$.

If $\gamma \neq 1$ then optimal expenditure choices do respond to changes in relative prices. The social planner internalizes the preferences of workers and therefore inherits their desire to smooth or substitute consumption across states. At low levels of relative risk aversion, when $\gamma<1$, workers are relatively uninterested in smoothing consumption and are willing to substitute from the good to the bad state of the world if the gross return of doing so, $\frac{1}{p}$, is greater than one. Therefore, with $\gamma<1$ the social planner will choose optimal benefit levels $b^{*}$ that exceed those obtained from the standard formulation in the Baily-Chetty model. However, virtually all calibrations consider levels of relative risk-aversion $\gamma>1$ more realistic. In this case, the result is reversed, and our formula deviates from the standard formulation in the direction of lower optimal benefit levels $b^{*}$. Therefore, for levels of relative risk aversion greater than one, estimations based on expenditure data systematically over-estimate the level of optimal unemployment benefits.

\section{Application: the optimal replacement ratio}

To gauge the practical importance of the distinction between consumption and expenditure we apply our condition describing the optimal unemployment insurance benefit to the United States. We use the approach by Gruber (1997), who uses consumption expenditure data to arrive at optimal replacement rates. Gruber's method has been ex- 
tremely influential and has been widely used in applied work bearing on unemployment insurance. $^{8}$

Gruber (1997) estimates a linear relationship between the expenditure drop at unemployment and the replacement rate $r=\frac{b}{w}$ of the form

$$
\Delta \log \tilde{c}=\alpha+\beta r .
$$

In this expression, $\alpha>0$ measures the gap of expenditure across employment states in the absence of unemployment benefits, and $\beta<0$ measures how this gap is narrowed as the replacement rate increases. Once these parameters have been estimated, substituting Gruber's specification into the above equation permits to isolate $r$ as a function of the elasticity of the duration with respect to benefits $\varepsilon_{D, b}$ and the relative price $p$ of a unit of consumption in the unemployed state.

In our calculations we adopt the baseline estimates by Gruber (1997): $\hat{\alpha}=0.222$ and $\hat{\beta}=-0.265$. With these estimates, consumption expenditure at average replacement rates falls by roughly $10 \%$ when a worker enters unemployment. We follow the literature and set the duration elasticity $\varepsilon_{D, b}=0.500$. This value is based on the survey by Krueger and Meyer (2002). ${ }^{9}$ We present results for a range of levels of relative risk-aversion $\gamma$ that go from 1 to 5 .

To calibrate $p$, we use the results by Aguiar and Hurst (2005), who estimate the effect of unemployment on food expenditure and food consumption for a cross-section of US households. Aguiar and Hurst (2005) construct a consumption index to map quantity data into a permanent income measure. In their sample, unemployment reduces food expenditure by $19 \%$ and food consumption by $5 \%$. This implies that in their data almost three-quarters of the drop in expenditure are due to a lower price per unit of consumption. With an average drop of $10 \%$ in expenditure caused by unemployment, the corresponding value for $p$ would be 0.925 .

The $19 \%$ drop in expenditure due to unemployment estimated by Aguiar and Hurst (2005) is relatively large compared to the usual estimates, which hover around $10 \%$ (e.g., Stephens, 2001). Assuming that their consumption index is correctly estimated,

\footnotetext{
${ }^{8}$ Recent examples of studies using Gruber's approach include Browning and Crossley (2001) and Bronchetti (2012).

${ }^{9}$ In the Appendix we re-calculate our results for $\varepsilon_{D, b}=0.432$, the value preferred by Gruber (1997), using the linear approximation in (22).
} 
we therefore believe that $p=0.950$ might be a more likely value. ${ }^{10}$ In Table 1 we present optimal replacement rates calculated for the whole range of values that go from no price drop $(p=1.000)$ to a 10 percent price drop $(p=0.900)$. This last value implies that the fall in expenditure is entirely due to the price change.

Table 1: Optimal replacement ratio

\begin{tabular}{crrrrr}
\hline Level of RRA & \multicolumn{5}{c}{ Relative price ratio $p$} \\
\cline { 2 - 6 }$\gamma$ & $\mathbf{1 . 0 0 0}$ & $\mathbf{0 . 9 7 5}$ & $\mathbf{0 . 9 5 0}$ & $\mathbf{0 . 9 2 5}$ & $\mathbf{0 . 9 0 0}$ \\
\hline $\mathbf{1 . 0}$ & 0.000 & 0.000 & 0.000 & 0.000 & 0.000 \\
$\mathbf{1 . 5}$ & 0.000 & 0.000 & 0.000 & 0.000 & 0.000 \\
$\mathbf{2 . 0}$ & 0.160 & 0.112 & 0.063 & 0.013 & 0.000 \\
$\mathbf{2 . 5}$ & 0.296 & 0.238 & 0.180 & 0.119 & 0.057 \\
$\mathbf{3 . 0}$ & 0.386 & 0.322 & 0.257 & 0.190 & 0.121 \\
$\mathbf{3 . 5}$ & 0.451 & 0.382 & 0.312 & 0.240 & 0.167 \\
$\mathbf{4 . 0}$ & 0.499 & 0.427 & 0.354 & 0.278 & 0.201 \\
$\mathbf{5 . 0}$ & 0.567 & 0.490 & 0.412 & 0.331 & 0.249 \\
\hline
\end{tabular}

The first column of Table 1 shows the optimal replacement ratio as a function of relative risk-aversion in the case in which the distinction between consumption and expenditure is irrelevant $(p=1)$. The values in this column are approximately equal to those of Gruber (1997, p. 203, Table 4, Col. 1). The difference with Gruber's values is explained by our use of the exact expression in (21) rather than the linear approximation, and by our slightly higher choice of $\varepsilon_{D, b}{ }^{11}$

As we move to the columns on the right, increasing the gap between consumption and expenditure, optimal replacement ratios decrease and it becomes more difficult to reconcile the replacement rates with those prevailing in the US assuming reasonable values of relative risk-aversion. For example, for $p=0.950$ it takes a value of $\gamma$ of almost 5 to reach an optimal replacement rate of $40 \%$.

\footnotetext{
${ }^{10}$ Aguiar and Hurst (2005, pp. 943-944) make a comment that goes in this direction when they compare their consumption index to the 9\% drop in earnings six or more years after the onset of unemployment uncovered by Stevens (1997). Their reason for confronting their index with long-term earnings is that the consumption index is expressed in terms of permanent income dollars.

${ }^{11}$ In the Appendix we show that Gruber's results are exactly replicated once these changes are undone.
} 


\subsection{The consumption-expenditure wedge}

How exactly is the optimal replacement rate impacted by the distinction between consumption and expenditure? Using (21) and (23), the optimal replacement ratio can be written as

$$
r^{*}(p)=r^{*}(1)+\frac{1-\gamma}{\gamma \hat{\beta}} \log p .
$$

The value $r^{*}(1)$ corresponds to the replacement ratio if the distinction between consumption and expenditure were neglected (this is equivalent to assuming $p=1$ ) whereas $r^{*}(p)$ is the correct replacement ratio. We define the consumption-expenditure wedge $C E W$ as

$$
C E W(p ; \gamma, \beta) \equiv r^{*}(p)-r^{*}(1)=\frac{1-\gamma}{\gamma \hat{\beta}} \log p
$$

Focusing on the wedge $C E W$ is informative for a wider class of models that extend the original Chetty-Baily setup. These models lead to versions of (20) that include small variations but are overall similar to it. ${ }^{12}$ Because $p$ shows up in the optimization problem multiplying the marginal utility of consumption when unemployed, it is bound to show up in a way similar to (20) in generalizations of the standard Baily-Chetty formula.

The $C E W$ is solely a function of $p$ and parameters $\gamma$ and $\beta$. This dependence on a reduced set of parameters is interesting also from a purely empirical perspective. The calculations in Table 1 are influenced by variables that have only 'level effects' and do therefore not show up in the wedge. The duration elasticity $\varepsilon_{D, b}$ is one such variable. The other one is $\alpha$. Whereas there exists some degree of consensus on the value of $\varepsilon_{D, b}$, this is not the case with $\alpha{ }^{13}$

The parameter $\alpha$ measures the drop in expenditure that workers in the US would face in the absence of unemployment insurance. Of course, this is a counter-factual experiment that is never observed in real life. The estimated value of $\alpha$ is an extrapolation that owes its existence to the linear specification that was originally assumed by Gruber (1997), and which is reflected in equation (23). The slope parameter $\beta$, on the other hand, is identified primarily from local variation inside the range of values that are observed in

\footnotetext{
${ }^{12}$ Several of these studies are surveyed by Chetty and Finkelstein (2013, Section 3).

${ }^{13}$ There is still some uncertainty surrounding the correct value of $\varepsilon_{D, b}$. For example, some calibrations use values close to 0.75 whereas recent research by Meyer and Mok (2014) suggests a values in the range $0.1-0.2$.
} 
the data. By focusing on $C E W$ we therefore strip the empirical implications of our model from 'level effects' that can be a nuisance.

In Table 2 we show how the wedge depends on the choices of the relative risk-aversion parameter and the value of $p$. The values in this table show how much the optimal

Table 2: Optimal replacement ratio: deviations from a canonical Baily-Chetty formula

\begin{tabular}{crrrrr}
\hline Level of RRA & \multicolumn{5}{c}{ Relative price ratio $p$} \\
\cline { 2 - 6 }$\gamma$ & $\mathbf{1 . 0 0 0}$ & $\mathbf{0 . 9 7 5}$ & $\mathbf{0 . 9 5 0}$ & $\mathbf{0 . 9 2 5}$ & $\mathbf{0 . 9 0 0}$ \\
\hline $\mathbf{1 . 0}$ & 0.000 & 0.000 & 0.000 & 0.000 & 0.000 \\
$\mathbf{1 . 5}$ & 0.000 & -0.032 & -0.065 & -0.098 & -0.133 \\
$\mathbf{2 . 0}$ & 0.000 & -0.048 & -0.097 & -0.147 & -0.199 \\
$\mathbf{2 . 5}$ & 0.000 & -0.057 & -0.116 & -0.177 & -0.239 \\
$\mathbf{3 . 0}$ & 0.000 & -0.064 & -0.129 & -0.196 & -0.265 \\
$\mathbf{3 . 5}$ & 0.000 & -0.068 & -0.138 & -0.210 & -0.284 \\
$\mathbf{4 . 0}$ & 0.000 & -0.072 & -0.145 & -0.221 & -0.298 \\
$\mathbf{5 . 0}$ & 0.000 & -0.076 & -0.155 & -0.235 & -0.318 \\
\hline
\end{tabular}

replacement rate needs to be reduced if the distinction between consumption and expenditure is neglected as in the standard Baily-Chetty formula.

The values in this table confirm that the wedge is very sensitive to $p$. From the definition of CEW in (25), for $\gamma>1$ the wedge is always negative. The logarithmic function implies that departures of the price $p$ away from 1 lead to an effect on the wedge of increasing magnitude. This high sensitivity to $p$ highlights the need of having estimates of the parameter $p$ as precise as possible to calibrate optimal replacement rates.

\section{Concluding Remarks}

We have shown how the provision of optimal unemployment insurance is affected by the distinction between consumption and expenditure. By extending the Baily-Chetty model we derived a "sufficient statistics" formula for optimal unemployment insurance that is expressed in terms of observable variables and can therefore be readily used in applied work.

For levels of relative risk-aversion that exceed one, our formula indicates that optimal unemployment insurance benefits are lower when the distinction between consumption 
and expenditure is taken into account. A calibration to US data suggests that the effect of this distinction on the magnitude of optimal replacement rates is quantitatively large. There is abundant evidence on the magnitude of expenditure drops at unemployment for the US and for several other countries. In comparison, the evidence on price changes upon unemployment is still relatively scarce, with the possible exception of the US. Still, even in the case of the US, important research lies ahead. The evidence so far is for a reduced number of items (typically groceries) and is based on cross-sectional data. To calibrate the value of $p$, ideally, one would want to use panel-data estimates of prices paid on a wide range of goods by households transitioning into unemployment.

How much consumption-smoothing is achieved is an important attribute of any unemployment insurance scheme. In this paper we have shown that to correctly quantify the benefits of consumption-smoothing it is necessary to distinguish between consumption and expenditure. Because many social insurance programs have consumption insurance at their heart, this distinction will be relevant not only for the design of optimal unemployment insurance, but for social insurance programs in general. 


\section{Appendix: results for the linear approximation}

Because the results by Gruber (1997) are frequently used in applied work, we calculate comparable optimal replacement ratios using the linear approximation and parameter values assumed by Gruber (1997). In his calculations, Gruber (1997) assumed a duration elasticity $\varepsilon_{D, b}$ of 0.432 and used the linear approximation in (22). Table 3 exhibits optimal replacement ratios that are comparable to those in Table 4 of Gruber (1997).

Table 3: Optimal replacement ratio using the linear approximation and same parameter values as Gruber (1997)

\begin{tabular}{crrrrr}
\hline Level of RRA & \multicolumn{5}{c}{ Relative price ratio $p$} \\
\cline { 2 - 6 }$\gamma$ & $\mathbf{1 . 0 0 0}$ & $\mathbf{0 . 9 7 5}$ & $\mathbf{0 . 9 5 0}$ & $\mathbf{0 . 9 2 5}$ & $\mathbf{0 . 9 0 0}$ \\
\hline $\mathbf{1 . 0}$ & 0.000 & 0.000 & 0.000 & 0.000 & 0.000 \\
$\mathbf{1 . 5}$ & 0.000 & 0.000 & 0.000 & 0.000 & 0.000 \\
$\mathbf{2 . 0}$ & 0.023 & 0.000 & 0.000 & 0.000 & 0.000 \\
$\mathbf{2 . 5}$ & 0.186 & 0.129 & 0.072 & 0.016 & 0.000 \\
$\mathbf{3 . 0}$ & 0.294 & 0.231 & 0.169 & 0.106 & 0.043 \\
$\mathbf{3 . 5}$ & 0.372 & 0.305 & 0.237 & 0.170 & 0.102 \\
$\mathbf{4 . 0}$ & 0.430 & 0.359 & 0.289 & 0.218 & 0.147 \\
$\mathbf{5 . 0}$ & 0.512 & 0.436 & 0.361 & 0.285 & 0.210 \\
\hline
\end{tabular}

The values in the first column, in which $p=1$, replicate the values in the column denoted as the 'Base Case' in Table 4 of Gruber (1997). In comparison with Table 1, optimal replacement ratios are slightly lower than in Table 1 despite of the use of a slightly lower duration elasticity. The reason for this is the linear approximation error: in the approximation, Gruber (1997) sets $\varepsilon_{D, b}=0.432$ whereas the exact formula is effectively using $\log (1+0.500)=0.405$. 


\section{References}

Aguiar, M., And E. Hurst (2005): "Consumption versus Expenditure," Journal of Political Economy, 113(5), 919-948.

(2007): "Life-Cycle Prices and Production," American Economic Review, 97(5), $1533-1559$.

Aguiar, M., E. Hurst, and L. Karabarbounis (2013): "Time Use during the Great Recession," American Economic Review, 103(5), 1664-96.

BAILY, M. N. (1978): "Some aspects of optimal unemployment insurance," Journal of Public Economics, 10(3), 379-402.

Bronchetti, E. T. (2012): "Workers' compensation and consumption smoothing," Journal of Public Economics, 96(5), 495-508.

Browning, M., and T. F. Crossley (2001): "Unemployment insurance benefit levels and consumption changes.," Journal of Public Economics, 80, 1-23.

Chetty, R. (2006): "A general formula for the optimal level of social insurance," Journal of Public Economics, 90(10-11), 1879-1901.

(2009): "Sufficient Statistics for Welfare Analysis: A Bridge Between Structural and Reduced-Form Methods," Annual Review of Economics, 1(1), 451-488.

Chetty, R., And A. Finkelstein (2013): "Social Insurance: Connecting Theory to Data," in Handbook of Public Economics, ed. by M. F. Alan J. Auerbach, Raj Chetty, and E. Saez, vol. 5, chap. 3, pp. 111 - 193. Elsevier.

Cochrane, J. H. (1991): "A Simple Test of Consumption Insurance," Journal of Political Economy, 99(5), 957-76.

Gruber, J. (1997): "The Consumption Smoothing Benefits of Unemployment Insurance," American Economic Review, 87(1), 192-205.

Harberger, A. C. (1964): "The Measurement of Waste," The American Economic Review, 54(3), pp. 58-76.

Hopenhayn, H. A., And J. P. Nicolini (1997): "Optimal Unemployment Insurance," Journal of Political Economy, 105(2), 412-38.

Krueger, A. B., And B. D. Meyer (2002): "Labor Supply Effects of Social Insurance," Working Paper 9014, National Bureau of Economic Research.

Krueger, A. B., And A. I. Mueller (2012): "The Lot Of The Unemployed: A Time Use Perspective," Journal of the European Economic Association, 10(4), 765-794. 
Meyer, B. D., And W. K. MoK (2014): "A Short Review of Recent Evidence on the Disincentive Effects of Unemployment Insurance and New Evidence from New York State," National Tax Journal, 67(1), 219-252.

Shavell, S., And L. Weiss (1979): "The Optimal Payment of Unemployment Insurance Benefits over Time," Journal of Political Economy, 87(6), 1347-62.

Stephens, M. (2001): "The Long-Run Consumption Effects Of Earnings Shocks," The Review of Economics and Statistics, 83(1), 28-36.

Stevens, A. H. (1997): "Persistent Effects of Job Displacement: The Importance of Multiple Job Losses," Journal of Labor Economics, 15(1), 165-188. 